\title{
Breast Implant-Related Lesion
}

National Cancer Institute

\section{Source}

National Cancer Institute. Breast Implant-Related Lesion. NCI Thesaurus. Code C139013.

A lesion that develops in the breast tissue following breast implant placement. 